\title{
Periodontitis and Metabolic Control: A Preliminary Study
}

\author{
Periodontitis y Control Metabólico: Estudio Preliminar
}

\begin{abstract}
Gisele Maria Campos Fabri",**; Paulo Sérgio Rangel D’Alleva**; Simão Augusto Lottemberg ${ }^{* * *}$; Cynthia Savioli*; Mariana Yumi Takahashi Puerta** \& José Tadeu Tesseroli de Siqueira**
\end{abstract}

FABRI, G. M. C.; D’AlleVA, P. S. R.; LOTTEMBERG, S. A.; SAVIOLI, C.; PUERTA, M. Y. T. \& SIQUeIRA, J. T. T. Periodontitis and metabolic control: A preliminary study. Int. J. Odontostomat., 8(2):273-277, 2014.

ABSTRACT: The aim of this study was to evaluate the periodontal condition and the metabolic control of patients with diabetes mellitus type 2. Patients with diabetes mellitus type 2 were evaluated pre- and post (30 days) treatment of the periodontitis through the following exams: glycemia, glycosylated hemoglobin, plaque index, gingival bleeding index and periodontal pocket depth index. Periodontal treatment consisted of: Scaling, root planning and plaque control, associated with systemic antibiotic therapy with amoxicillin. Seventeen patients (12 women and 5 men; mean age $=55.94$ years) were included. The chief complaints were: gingival bleeding $(n=13)$; gingival pain $(n=8)$, tooth mobility $(n=3)$, gingival swelling $(n=2)$ and halitosis $(n=2)$. The mean time of these complaints ranged from 2 months to 20 years. None of them had ever received guidance on oral hygiene or dental assessment. There was a reduction in the following indexes (30 days after the periodontal treatment): plaque, from $41.79 \pm 24 \%$ to $12.26 \pm 13 \%)(p \leq 0.0005)$, gingival bleeding from $51.58 \pm 25 \%)$ to $15.77 \pm 15 \%$ $(p \leq 0.0005)$, periodontal pocket depth from $0.98 \pm 0.91 \mathrm{~mm}$ to $1.76 \pm 0.63 \mathrm{~mm})(p \leq 0.0005)$. In 15 patients there was a reduction in the glycosylated hemoglobin $(10.85 \pm 3.03 \%$ to $8.72 \pm 1.68 \%)(p \leq 0.0005)$. This preliminary study shows that patients of this sample had chronic and severe periodontal disease; there was a reduction in the glycosylated hemoglobin levels, but not of glycemia, 30 days after periodontal treatment. Long-standing studies are necessary; however patients with diabetes mellitus need control of chronic infections, including periodontal disease.

KEY WORDS: periodontal disease, diabetes mellitus, metabolic control.

\section{INTRODUCTION}

It has long been known that diabetes mellitus causes metabolic alterations attributed to hyperglycemia, like unspecific macroangiopathy (atherosclerosis and its multiple clinical expressions) and diabetic microangiopathy (Grant-Theule, 1996), and the advanced glycosylation end products (AGEs) are the main causes of these alterations (Brownlee et al., 1984). Excessive non-enzymatic glycerolization includes the deactivation of enzymes, inhibition of the regulation of union molecules, reduction in susceptibility to proteolysis, alteration of nucleic acid function and macromolecular recognition and increase of immunogenicity (Brownlee et al., 1984, 1992). The blood levels of glycosylated hemoglobin are important indicators of glucose metabolism in diabetic patients as they do not depend on the patient and may be assessed periodically (Mealy, 1996).
Among the factors aggravating diabetes mellitus are infections and more recently there are indications of the involvement of serious periodontal diseases as a risk factor for this systems disease (Miller et al., 1992; Grossi et al., 1996, 1997; Taylor et al., 1996; Genco et al., 1990). The bacteria and their products interact with the junctional epithelium and penetrate in the direction of the conjunctive tissue and induce an inflammatory response of the vascular plexus with consequent leucocitary migration, mainly by $B$ and $T$ lymphocytes which, on being stimulated, synthesize antibodies. Lipopolysaccharides, gram-negative bacteria and pro-inflammatory cytokines may enter the bloodstream in pathogenic numbers and cause damage at a distance (Amar \& Han 2003; John \& Kim, 2002; Jin et al., 2003). Furthermore, periodontal infection may induce accentuated and prolonged resistance to insulin (Yki-Järvinen et al., 1989).

" School of Dentistry, Universidade Federal de Juiz de Fora, Minas Gerais, Brazil.

" Dentistry Division, Hospital das Clínicas, Medical School, Universidade de São Paulo, São Paulo, Brazil.

** Medical Clinical, Department, Medical School, Universidade de São Paulo, São Paulo, Brazil. 
Recent studies indicate the involvement of severe periodontal disease in the glycosylated hemoglobin levels, although lighter gingival disease does not induce significant alterations (Smith et al., 1996). Even so, various factors are necessary for metabolic control of the diabetic, including the seriousness of periodontal disease, its treatment modality, the use of antibiotics, glycosylated hemoglobin plasmatic levels and the control of diabetes itself (Grossi \& Genco, 1998; Mealey \& Rethman, 2003).

Even though infections are considered to be potential risk factors for chronic systemic disease, like diabetes mellitus itself, there is still no medical routine for the periodontal assessment of these patients, in spite of it being a frequent disease in the population in general.

Thus, the aim of this study was to evaluate patients with diabetes mellitus type II, treated at a large teaching hospital, to observe: a) the presence of severe periodontal disease and $b$ ) the levels of glycosylated hemoglobin and glycemia pre- and short-time after periodontal treatment.

\section{MATERIAL AND METHOD}

Twenty patients with diabetes mellitus type II were referred by the Clinical Medical Department (Endocrinology) of a large teaching hospital to the Dentistry Division of the same hospital. Included patients presented poor glycemic control and severe periodontal disease, according to the Nyman \& Lindhe (1989) clinical index. Patients with nephropathies, cardiopathies, diabetic neuropathies and other types of infections (urinary, respiratory tract and gastro-intestinal tract) were excluded. Three patients did not return for the final assessment.

The following assessment and treatment protocol was followed:

1-Assessment of complaints in the oral cavity and oral hygiene habits. Clinical periodontal assessment according to the Ainamo \& Bay (1975) bleeding index and the O'Leary (1972) plaque index, as well as the clinical insertion level measurements.

2- Radiographic and orthopantographic examination of the face.

3- Laboratory examination of glycemia and glycosylated hemoglobin.
4- Detailed instructions about oral hygiene.

5- Periodontal scraping carried out in a minimum of 2 sessions and a maximum of four.

6- Antibiotic therapy for ten days (amoxicillin every 8 hours).

7- Reassessment 30 days after the end of periodontal treatment by means of the same exams carried out pre-operatively.

Statistical method. To evaluate the nature of the distribution of the values of the variables or the variability of the measurements the Student's t test was applied to 2 independent samples. The level of significance was set at $5 \%(p<0.05)$.

All the patients gave informed consent to procedures approved by the Ethics Committee of the Medical School.

\section{RESULTS}

Seventeen patients ( 12 women and 5 men) mean age of $55.94 \pm 12,03$ years were assessed and treated. Fifteen patients referred orofacial pain or discomfort like gingival bleeding, gingival pain, tooth mobility and halitosis. The mean time of these complaints ranged from 2 months to 20 years. With regard to oral hygiene, 15 affirmed that they brushed their teeth 3 times a day, 3 brushed twice a day and 1 brushed once a day. All affirmed never having received instructions about oral hygiene. The last dental treatment ranged from 5 months to 20 years. The current use medications were oral hypoglycemic and anti-hypertensive agents. Fourteen patients presented arterial hypertensive. The demographic data and general characteristics of the sample are showed in Table I.

After 30 days had elapsed after treatment, all the patients presented with reduced plaque, bleeding and probe depth indexes. There was a statistically significant difference $(p<0.0005)$ between the bleeding and plaque indexes and in the probing depth compared before and 30 days after treatment. All the patients showed improvement of plaque, bleeding and probe depth indexes 30 days after periodontal treatment $(p<0.05)$. The periodontal parameters at baseline and after therapy are showed in Table II. 
Table I. Clinical characteristics of patients with diabetes mellitus type II and periodontal disease $(n=17)$.

\begin{tabular}{ll}
\hline Sex & Men= 5; Women= 12 \\
Age (range) & $55.94 \mathrm{y}( \pm 12.03)$ \\
Age at onset of the diabetes mellitus & $52.47 \mathrm{y}$ \\
Diabetes mellitus duration & 0.5 to $19 \mathrm{y}$ \\
Oral complaints & Gingival bleeding= $13(76.47 \%)$ \\
& Tooth mobility= 3 $(17 \%)$ \\
& Gingival swelling: $2(11 \%)$ \\
& Halitosis = 2 $(11 \%)$ \\
& Dentinal sensitivity= $1(5.88 \%)$ \\
Last dental treatment & 2 months to 20 years \\
\hline$y=$ years. &
\end{tabular}

Table II. Assessment of the periodontal condition and metabolic control of diabetes mellitus baseline and 30 days after treatment $(n=17)$.

\begin{tabular}{lcc}
\hline & $\begin{array}{c}\text { Baseline } \\
\text { (means) }\end{array}$ & $\begin{array}{c}\text { Thirty days after treatment } \\
\text { (means) }\end{array}$ \\
\hline Bleeding Index & $51.58+25$ & $15.77+15^{* *}$ \\
Plaque Index & $41.79 \pm 24$ & $12.26 \pm 13^{* *}$ \\
Probing Depth & $2.98 \pm 0.91 \mathrm{~mm}$ & $1.76 \pm 0.63 \mathrm{~mm}^{* *}$ \\
Glycemia & $169.23+68.02$ & $161.46+58.29^{*}$ \\
Glycosylated hemoglobin & $10.46 \pm 3.03$ & $8.60 \pm 1.68^{* *}$ \\
\hline
\end{tabular}

${ }^{*} p=0.3318 ;{ }^{* *} p<0.0005$

\section{DISCUSSION}

The data in this study showed that periodontal treatment significantly reduced all periodontal parameters [bleeding index $(p=0.0005)$, plaque index $(p=0.0004)$ and pocket depth $(p=0.0004)$. Periodontal health are fundamental for reducing transitory bacteremia, which may be a particular risk in susceptible patients (Siqueira \& Teixeira 2001) or contribute to an aggravation in metabolic conditions like those of diabetes mellitus (Page, 1998). Furthermore, it is known that acute infections cause resistance to insulin, diminishing glucose absorption (Yki-Järvinen et al.) and that the same may occur in chronic periodontal infections, which would make metabolic control of the diabetic difficult and would contribute to an increased resistance to insulin (Grossi \& Genco).

The reduction in the glycosylated hemoglobin levels 30 days after periodontal treatment, in 15 patients shows that the control of this disease may modulate the glycosylated hemoglobin blood levels, as in this period the patients did not receive any other treatment for diabetes, other than that they used to carry out previously. However we need to see these results carefully, because of the short-time follow-up. Longstanding studies are necessary.
The glycated hemoglobin levels reflects the chronic exposure of hemoglobin to hypergliicemia (Mealey \& Rethman, 2003). Thus, glycosylated hemoglobin is considered as an indicator to metabolic control (Grossi et al., 1996).

The data in the present study do not show any significant alteration in the blood glucose levels (an average from $169.23 \pm 68.02$ to $161.64 \pm 58.29$ ), like previous studies, in which patients with better glycemic control did not have variations in the glycosylated hemoglobin levels, which were close to normal (Grossi et al., 1996, 1997; Grossi \& Genco; Sepälä \& Ainamo, 1994; Smith et al.), as possibly occurred with two patients in the present study. The benefit of periodontal treatment on the glycosylated hemoglobin rate would appear to depend on the control of diabetes, and would not appear to have good results in patients with deficient control. The periodontal treatment effect on glycosylated hemoglobin level appear to depend of metabolic control (Seppälä \& Ainamo).

It is also interesting to note that the majority of the patients assessed related complaints compatible with chronic periodontal disease, like gingival pain $(47.05 \%)$, tooth mobility $(17 \%)$, gingival bleeding $(76.47 \%)$ and halitosis $(11 \%)$. On the other hand, some did not even remember when last they had consulted 
a dentist. Culturally, irrespective of its seriousness, periodontal diseases are underestimated by patients and even by health professionals, mainly among the poorer populations (Siqueira \& Teixeira; Bridges et al., 1996), which have other diseases or problems considered as priorities. Chronic systemic diseases, like diabetes mellitus itself, end up being the main concern of patients, which increases the responsibility of the doctor responsible for the patient to identify all the risk factors and provide the necessary treatment.

These data reinforce the importance of assessing the periodontal condition of patients with diabetes mellitus type II, which would be priority in patients considered to be difficult to control, already at the diagnostic stage of the systemic disease. Periodontal disease, as an infectious disease requires immediate treatment irrespective of the socio-economic condition of the analyzed population. Its diagnosis should be routine in all patients with chronic systemic diseases, which suffer the influence of infections, and a warning particularly in cases considered to be difficult to control the systemic condition. Furthermore, diabetic patients may be motivated with regard to the importance of oral health for controlling their systemic diseases. In this assessment, no patient had ever received any guidance about oral hygiene.

The use of systemic antibiotic associated with mechanical periodontal therapy would seem to have contributed to better results as regards the glycosylated hemoglobin rate (Grossi et al., 1997). Doxiciclin is one of the ones indicated (Miller et al., 1992), in addition to amoxicillin, which penetrates the gingival fluid at levels compared to blood levels and is effective against the majority of periodontal pathogens (Gordon \& Walker, 1993). Thus amoxicillin was opted for because of the availability of the drug, ease of use by patients and obtainment at the hospital, and because it has fewer side effects.

In conclusion, the data in this study showed that the patients assessed a) presented with signs and symptoms of long standing chronic and severe periodontal disease and $b$ ) the periodontal treatment decreased all the indexes of the periodontal disease; c) there were decreased of the glycosylated hemoglobin levels in the period of 30 days after periodontal treatment. These data reinforce the need to evaluate the periodontal condition of patients with diabetes mellitus type 2 , because infections, as those that occur in chronic periodontal disease, may be a risk factor for metabolic control of diabetes mellitus.
FABRI, G. M. C.; D'ALLEVA, P. S. R.; LOTTEMBERG, S. A.; SAVIOLI, C.; PUERTA, M. Y. T. \& SIQUEIRA, J. T. T. Periodontitis y control metabólico: Estudio preliminar. Int. J. Odontostomat., 8(2):273-277, 2014.

RESUMEN: El objetivo fue evaluar la condición periodontal y el control metabólico de pacientes con diabetes mellitus tipo 2. En los pacientes con diabetes mellitus tipo 2 se evaluaron previo y posterior (30 días) al tratamiento de la periodontitis los siguientes exámenes: glucemia, hemoglobina glicosilada, índice de placa bacteriana, índice de sangrado gingival e índice de profundidad de la bolsa periodontal. El tratamiento periodontal consistió en: curetage, alisado radicular y control de placa, asociado a la terapia sistémica antibiótica con amoxicilina. Se evaluaron 17 pacientes (12 mujeres y 5 hombres, con una edad media de 55,94 años). Las principales complicaciones fueron: sangrado gingival $(n=13)$, dolor gingival $(n=8)$, movilidad dental $(n=3)$, edema gingival $(n=2)$ y halitosis $(n=2)$. El tiempo medio de estas complicaciones varió entre 2 meses y 20 años. Ninguno de ellos reconoció haber recibido orientación sobre higiene oral o evaluación dental. Hubo una reducción (30 días después del tratamiento periodontal) en los siguientes índices: placa, de $41,79 \pm 24 \%$ a $12,26 \pm 13 \%$ ) ( $p \leq 0,0005)$; sangrado gingival, de $51,58 \pm 25 \%$ ) a $15,77 \pm 15 \%$ ( $\leq \leq 0,0005)$, profundidad de la bolsa periodontal, de $0,98 \pm 0,91 \mathrm{~mm}$ a $1,76 \pm 0,63 \mathrm{~mm})(\mathrm{p} \leq 0,0005)$. En 15 pacientes se observó una reducción en la hemoglobina glucosilada $(10,85 \pm 3,03 \%$ a $8,72 \pm 1,68 \%)(p \leq 0,0005)$. Observamos que los pacientes de esta muestra tenían enfermedad periodontal crónica y severa; que hubo una reducción en los niveles de hemoglobina glucosilada, pero no de la glucemia, 30 días después del tratamiento periodontal. Estudios longitudinales son necesarias, sin embargo los pacientes con diabetes mellitus requieren control de las infecciones crónicas, como la enfermedad periodontal.

PALABRAS CLAVE: enfermedad periodontal, diabetes mellitus, control metabólico.

\section{REFERENCES}

Ainamo, J. \& Bay, I. Problems and proposals for recording gingivitis and plaque. Int. Dent. J., 25(4):229-35, 1975.

Amar, S. \& Han, X. The impact of periodontal infection on systemic diseases. Med. Sci. Monit., 9(12):RA291-9, 2003.

Bridges, R. B.; Anderson, J. W.; Saxe, S. R.; Gregory, K. \& Bridges, S. R. Periodontal status of diabetic and nondiabetic men: effects of smoking, glycemic control, and socioeconomic factors. J. Periodontol., 67(11):1185-92, 1996.

Brownlee, M.; Vlassara, H. \& Cerami, A. Nonenzymatic glycosylation and the pathogenesis of diabetic complications. Ann. Inter. Med., 101(4):527-37, 1984. 
Brownlee, M. Glycation products and the pathogenesis of diabetic complications. Diabetes Care, 15(12):1835-43, 1992.

Genco, R. J.; Wilson, M. E. \& Nardin, E. D. Periodontal complications and neutrophil abnormalities. In: Genco, R. J.; Goldman, H. M. \& Cohen, D.W. (Eds.). Contemporary Periodontics. St. Louis, Mosby, 1990. pp.203-20.

Gordon, J. M. \& Walker, C. B., Current status of systemic antibiotic usage in destructive periodontal disease. $J$. Periodontol., 64(8):760-71, 1993.

Grant-Theule, D. A. Periodontal disease, diabetes, and immune response: a review of current concepts. J. West Soc. Periodontol. Periodontal. Abstr., 44(3):69-77, 1996.

Grossi, S. G.; Skrepcinski, F. B.; DeCaro, T.; Zambon, J. J.; Cummins, D. \& Genco, R. J. Response to periodontal therapy in diabetics and smokers. J. Periodontol., 67(10):1094-102, 1996.

Grossi, S. G.; Skrepcinski, F. B.; DeCaro, T.; Robertson, D. C.; Ho, A. W.: Dunford, R. G. \& Genko, R. J. Treatment of periodontal disease in diabetics reduces glycated hemoglobin. J. Periodontol., 68(8):713-9, 1997.

Grossi, S. G. \& Genko, R. J. Periodontal disease and diabetes mellitus: a two-way relationship. Ann. Periodontol., 3(1):51-61, 1998.

Jin, L. J.; Chiu, G. K. \& Corbert, E. F. Are periodontal diseases risk factors for certain systemic disorders--what matters to medical practitioners? Hong Kong Med. J., 9(1):31-7, 2003.

John, V. \& Kim, S. J. Periodontal disease and systemic disease. Clinical information for the practicing dentist. $J$. Indiana Dent. Assoc., 81(2):15-8, 2002.

Mealey, B. L. Periodontal implications: medically compromised patients. Ann. Periodontol., 1(1):256-321, 1996.

Mealey, B. L. \& Rethman, M. P. Periodontal disease and diabetes mellitus. Bidirectional relationship. Dent. Today, 22(4):107-13, 2003.

Miller, L. S.; Manwell, M. A.; Newbold, D.; Reding, M. E.; Rasheed, A.; Blodgett, J. \& Kornman, K. S. The relationship between reduction in periodontal inflammation and diabetes control: a report of 9 cases. J. Periodontol., 63(10):843-8, 1992.

Nyman, S. \& Lindhe, J. Examination of patients with periodontal disease. In: Lindhe, J. (Ed.). Textbook of clinical peridontology. 2nd ed. Copenhagen, Munksgaard, 1989. pp.310-22.
O'Leary, T. J.; Drake, R. B. \& Naylor, J. E. The plaque control record. J. Periodontol., 43(1):38, 1972.

Page, R. C. The pathobiology of periodontal diseases may affect systemic diseases: inversion of a paradigm. Ann. Periodontol., 3(1):108-20, 1998.

Seppälä, B. \& Ainamo, J. A site-by-site follow-up study on the effect of controlled versus poorly controlled insulindependent diabetes mellitus. J. Clin. Periodontol., 21(3):161-5, 1994.

Siqueira, J. T. T. \& Teixeira, M. J. Dor orofacial: diagnóstico, terapêutica e qualidade de vida. Curitiba, Maio, 2011.

Smith, G. T.; Greenbaum, C. J.; Johnson, B. D. \& Persson, G. R. Short-term responses to periodontal therapy in insulin-dependent diabetic patients. J. Periodontol., 67(8):794-802, 1996.

Taylor, G. W.; Burt, B. A.; Becker, M. P.; Genco, R. J.; Shlossman, M.; Knowler, W. C. \& Pettit, D. J. Severe periodontitis and risk for poor glycemic control in patients with non-insulin-dependent diabetes mellitus. J. Periodontol., 67(10 Suppl.):1085-93, 1996.

Yki-Järvinen, H.; Sammalkorpi, K.; Koivisto, V. A. \& Nikkilä, E. A. Severity, duration, and mechanisms of insulin resistance during acute infections. J. Clin. Endocrinol. Metab., 69(2):317-23, 1989.

Correspondence to:

Dr. Gisele Maria Campos Fabri

Rua Oscar Vidal 469 - Centro

Juiz de Fora - MG

BRAZIL

Email: jfabri@uol.com.br

Received: 09-04-2014

Accepted: 08-05-2014 